\title{
Albanian Dentist's Attitude towards Pain-Free Local Anesthetics in Children, A Country Profile
}

\author{
Dorjan Hysi ${ }^{1}$, Esber Caglar ${ }^{2}$, Etleva Droboniku${ }^{1}$, Celjana Toti ${ }^{1}$, Enida Petro ${ }^{1}$, Ozgur Onder \\ Kuscu $^{2}$
}

${ }^{1}$ University of Medicine of Tirana, Albania, ${ }^{2}$ Private Practice, Pediatric Dentistry, Tirana, Albania

\begin{abstract}
Aim: The aim of this study was to access the Albanian dentist's attitude and perception toward pain-free dental injections in children. Methods: The survey was conducted in Tirana, Albania. A questionnaire regarding the dentist's attitude toward "Pain-free Local Anesthetic Techniques in Children" was used. It was structured as anonymous with six closed-ended questions in a Liker scale. Also, dentist information about gender, age, region and years of practice was part of the form. The information collected was analyzed using IBM SPSS 20. Descriptive statistics and one way ANOVA was used in comparing groups. The results were evaluated within a $95 \%$ confidence interval. Statistical significance level was established at $\mathrm{p}<0.05$.

Results: A total of 203 dentists were included in the study. 86 (42.4\%) were male and 117 (57.6\%) were female dentists. Their mean age was 35 years old (sd 10.1) and the mean clinical practice experience was 10 years old (sd 9.5). 72 (35.5\%) of dentists believed that pain is inevitable during local anesthesia in children and $158(77.8 \%)$ agreed that cotton pallet should be better applied as a topical anesthetics. $128(63 \%)$ of dentists believed in the possibility of pain-free local anesthesia in children. There was a higher agreement in males but not statistically significant. There was a statistically significant higher agreement between dentists in Tirana (the capital) $\mathrm{p}<0.03$ compared with the other regions while experience $(\mathrm{p}<0.2)$ and age $(\mathrm{p}<0.9)$ did not show any significant change Conclusions: A higher proportion of Albanian dentists believe the importance of pain free dental injections in children. Especially dentists in urban seem to perform pain-free LA injections.
\end{abstract}

Key Words: Albania, Dental education, Dental analgesia, Pain-free

\section{Introduction}

Pain in dentistry has been for many years one of the factors keeping patients away from dental settings. Even though the developing technologies are improving the quality of care still dental injections remain the popular method of anesthesia among the dental profession. Recent studies indicate that fear from intra-oral injections was found to keep the patients away from necessary treatment [1-5]. This might be the case in early childhood that will derive the same behavior to following ages. Pain-Free dental treatment is a keystone of creating a motivated group of young children who will establish better oral hygiene and follow the recall system. While implementing a 'pain-free dental treatment', pain-free dental anesthesia is compulsory. It has been recently advised that following a two minutes topical anesthetic application, slow and low-pressure injections are the key to pain-free and comfortable delivery of local anesthetic and named as "Painfree local anesthesia technique" [6]. It is questionable if this procedure is well practiced in dental schools and if it has been widely used among dentists throughout dental practices. Probably this might be a cost-effective technique especially in countries with developing economies and low economic status where the dental diseases prevalence is high and also there are difficulties to implement the costly technologies [7]. Albania is a small Eastern European country undergoing through economical, health care and education system changes to become an EU member. There are a few pediatric dentists in Albania and $95 \%$ of the treatment is performed by a general dentist. The small size dental community would give us the chance to receive a nationwide perception about certain dental techniques. Therefore the aim of this study was to access the Albanian dentist's attitude and perception toward pain-free dental injections in children.

\section{Methods}

The study protocol was approved by the Albanian Dental Association and Faculty of Dental Medicine of Tirana.

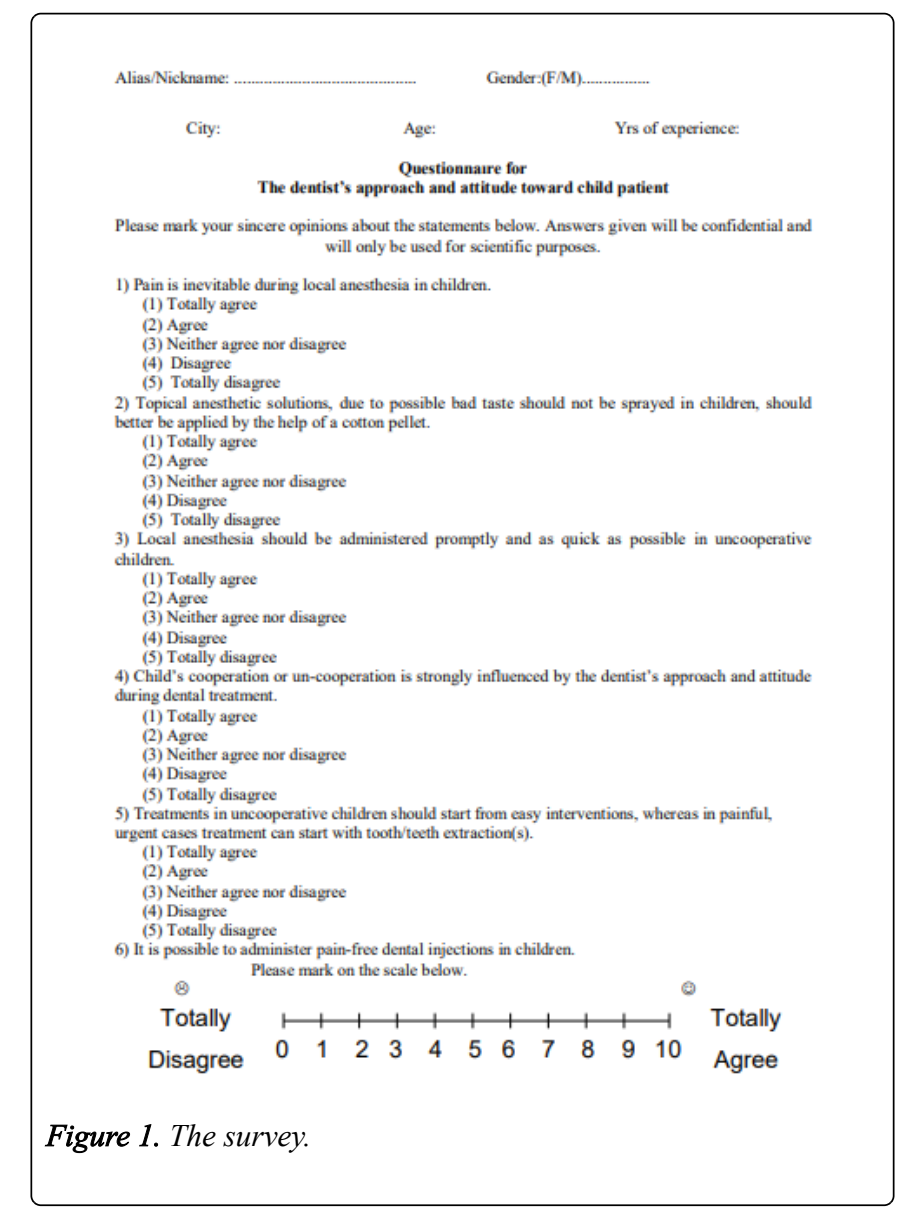


There was no need to obtain consent prior to the study since it was not an intervention study and the participation of the dentists was voluntary. The survey was conducted in Tirana, Albania. A questionnaire regarding the dentist's attitude toward "Pain-free Local Anesthetic Techniques in Children", was used. It was structured as anonymous with six closedended questions in a Liker scale. Also, dentist information about gender, age, region and years of practice was part of the form. The study was conducted in a one-page survey (Figure 1) as recently defined by Kuscu et al [8-10].

Table 1. Favorite answers to question statements on the survey of pain-free local anesthesia in children.

\begin{tabular}{|l|l|}
\hline Statement & Favorable answers \\
\hline $1^{\text {st }}$ statement & 4 and 5 \\
\hline $2^{\text {nd }}$ statement & 1 and 2 \\
\hline $3^{\text {rd }}$ statement & 4 and 5 \\
\hline $4^{\text {th }}$ statement & 1 and 2 \\
\hline $5^{\text {th }}$ statement & 4 and 5 \\
\hline $6^{\text {th }}$ statement & $>5$ \\
\hline
\end{tabular}

Dentists were advised to respond based on their own opinions and to ensure confidentiality a nickname should be used. It was distributed to the dentists participating in the $20^{\text {th }}$ Annual Dental Conference in Albania. This was the main dental event of the year with the highest number of participants from the country and abroad. There was no time limit for filling the questionnaire and it was not obligatory. They were distributed at the beginning of the first session and the filled questionnaires were collected at the end of it. In order to have comparable data, average values of age and experience in years were recorded since almost half of the dentist practice in the City of Tirana (the capital) the answers were compared regarding whether they work in Tirana or outside. The favorite answers to the question statements were put on Table 1.

\section{Statistical Analysis}

Statistical calculations were performed with IBM SPSS v.20 for standard descriptive statistical calculations and one way ANOVA tests for comparison of groups. The results were evaluated within a $95 \%$ confidence interval. Statistical significance level was set at $\mathrm{p}<0.05$.

\section{Results}

The participants who completed the questionnaire were 203 dentists aged between $24-70$ years. $86(42.4 \%)$ were male and $117(57.6 \%)$ were female dentists. Their gender, age, city of practice and yrs. of experience are shown in Table 2.

Table 2. Demographic data of Albanian dentists participating in the study.

\begin{tabular}{|l|l|l|}
\hline Gender & $\mathbf{n}$ & $\%$ \\
\hline Female & 117 & 57.6 \\
\hline Male & 86 & 42.4 \\
\hline Age & \multicolumn{2}{|l|}{ Mean age (SD) } \\
\hline & \multicolumn{2}{|l|}{$35(10.1)$} \\
\hline City & \multicolumn{2}{|l|}{} \\
\hline Tirane & 102 \\
\hline $\begin{array}{l}\text { Vlore, Shkodra, Durres, Elbasan, Berat, Lezhe, Fier, } \\
\text { Korça }\end{array}$ & 101 \\
\hline \multirow{2}{*}{ Years of experience } & \multicolumn{2}{|l|}{ Mean years (SD) } \\
\cline { 2 - 3 } & 10 (9.5) & \\
\hline
\end{tabular}

Table 3. Albanian dentists' attitude for the possibility of pain-free local anesthesia in children.

\begin{tabular}{|c|c|c|c|c|c|c|c|c|c|}
\hline & Gender & Age & Experience & & & & & & \\
\hline Statement & & & & 1 & 2 & 3 & 4 & 5 & 6 \\
\hline Favorite answer & & & & 5 & 1 & 5 & 1 & 5 & 10 \\
\hline Painfree (Choice 4-5) & 0.61 & 34.31 & 9.93 & 4.16 & 2.15 & 2.87 & 1.77 & 2.92 & 7.73 \\
\hline Impossible (Choice 1-2-3) & 0.55 & 35.27 & 10.64 & 2.19 & 2.01 & 2.64 & 2.03 & 2.78 & 5.48 \\
\hline
\end{tabular}

Table 4. Favorable answers for pain-free anesthesia by gender.

\begin{tabular}{|l|l|l|l|l|l|l|l|l|l|}
\hline & Gender (F) & $\begin{array}{l}\text { Mean age } \\
\text { (years) }\end{array}$ & Experience (years) & \multicolumn{3}{|l|}{} \\
\hline Statement & & & & 1 & 2 & 3 & 4 & 5 & 6 \\
\hline Favorite answer & & & & 5 & 1 & 5 & 1 & 5 & 10 \\
\hline Tirane & $0.65^{*}$ & 32.32 & $8.29^{* *}$ & 3.27 & 2.07 & 3.05 & 1.79 & 2.89 & 6.88 \\
\hline Other city & 0.49 & 37.44 & 12.42 & 2.95 & 2.08 & 2.43 & 2.03 & 2.79 & 6.16 \\
\hline${ }^{*} \mathrm{p}<0.03 ;{ }^{* *} \mathrm{p}=0.2$ & & & & & & & & \\
\hline
\end{tabular}

Their mean age was 35 years old (SD 10.1) and the mean clinical practice experience was 10 years old (SD 9.5). 72
$(35.5 \%)$ of dentists believed that pain is inevitable during local anesthesia in children and $158(77.8 \%)$ agreed that 
cotton pallet should be better applied as a topical anesthetics. $128(63 \%)$ of dentists believed in the possibility of pain-free local anesthesia in children. Dentists who answered the $1^{\text {st }}$ statement with favorable choices (4 and 5) gave much more favorable answers (yellows) for pain-free anesthesia (Table 3).

There was a higher agreement in males but not statistically significant $(\mathrm{p}>0.05)$. There was a statistically significant higher agreement between female dentists in Tirana (the capital) $(\mathrm{p}<0.03)$ compared with the other regions while their years of experience $(p=0.2)$ and age (p: 0.9) did not show any significant change (Tables 4-6).

Table 5. Favorable answers for pain-free anesthesia using the mean age as cut off.

\begin{tabular}{|l|l|l|l|l|l|l|l|}
\hline & $\begin{array}{l}\text { Exp. in } \\
\text { years }\end{array}$ & \multicolumn{6}{|l|}{$\mid$} \\
\hline Statement & & 1 & 2 & 3 & 4 & 5 & 6 \\
\hline Favorite answer & & 5 & 1 & 5 & 1 & 5 & 10 \\
\hline$>35$ & 21.58 & 2.98 & 2.09 & 2.54 & 1.82 & 2.35 & 6.6 \\
\hline$<35$ & 4.99 & 3.17 & 2.07 & 2.85 & 1.95 & 3.07 & 6.5 \\
\hline
\end{tabular}

Table 6. Favorable answers for pain-free anesthesia using the mean years of clinical experience as cut off.

\begin{tabular}{|l|l|l|l|l|l|l|l|}
\hline & Age & & & & & & \\
\hline Statement & & 1 & 2 & 3 & 4 & 5 & 6 \\
\hline Favorite answer & & 5 & 1 & 5 & 1 & 5 & 10 \\
\hline$>10$ & 45.13 & 2.99 & 2.06 & 2.6 & 1.92 & 2.4 & 6.61 \\
\hline$<10$ & 28.52 & 3.19 & 2.08 & 2.84 & 1.9 & 3.11 & 6.48 \\
\hline
\end{tabular}

\section{Discussion}

A small European nation, Albania, has little excess to dental services. Recent literature indicates that Albanian children had a high dental caries experienced, untreated cavities [11] and numerous dental disorders such as Molar Incisor Hypomineralization [12]. Thus this dilemma highlights the importance of local anesthesia for children.

It is assumed that to learn what Albanian practitioners think of pain-free local anesthesia, would better serve the children and the nation regarding dental health. Hitherto education of new generation dentist would also benefit from the conclusive remarks. For the last decade serving painless local anesthesia [13-15] was regarded as a new step, while it is questionable if it was widespread among Albanian dentists. In the present study, favorable or expected answers for pain-free anesthesia were noted and given answers were calculated to have an average value regarding each demographic data. Choice 3 "Neither agree nor disagree" was considered unfavorable for a pain-free outcome due to its hesitant meaning. Results seem to report that younger, female and dentists working in Tirane (or in a big city where competition is high) care more for pain. Doctors who believe in pain-free injections, seem to give more correct answers to statements (2, 3, 4 and 5) which also require some theoretical knowledge.

\section{Conclusion}

A higher proportion of Albanian dentists believe the importance of pain-free dental injections in children. Especially dentists in urban seem to perform pain-free LA injections.

\section{References}

1. Berge KG, Agdal ML, Vika M, Skeie MS. High fear of intraoral injections: prevalence and relationship to dental fear and dental avoidance among 10 to 16-yr-old children. European Journal of Oral Sciences. 2016; 124: 572-579.

2. Kuscu OO, Akyuz S. Children's preferences concerning the physical appearance of dental injectors. Journal of Dentistry for Children (Chic). 2006; 73: 116-121.

3. Kuscu OO, Akyuz S. Is it the injection device or the anxiety experienced that causes pain during dental local anesthesia? International Journal of Paediatric Dentistry. 2008; 18: 139-145.

4. Wilson S. Nonpharmacologic Issues. In: Pain perception and control. Pinkham; Casamassimo; Fields; Mc Tigue; Novak-Editors. Pediatric dentistry, infancy through adolescence. 3rd Ed. Pennsylvania: Saunders Company: 1999: 74-83.

5. Kuscu OO. Examination of children's pain and anxiety by psychometric, physiologic and observational methods during dental treatment and local anesthesia by two different dental injectors (dissertation). Istanbul: Marmara University, Institute of Health Sciences, Istanbul. 2006.

6. Welbury RR. Management of pain and anxiety. NewYork: Oxford University Pres. Pediatric Dentistry. 2001: 51-75.

7. Hysi D, Droboniku E, Toti C. Caries experience and treatment needs among Albanian 12-year-olds. Community Dental Health Journal. 2014; 31: 141-144.

8. Kuscu OO, Kucuktepe C, Caglar E, Cildir SK, Hacinlioglu N, et al. Role of student-to-student local analgesia administration on undergraduate students' opinions regarding pain-free local analgesia technique in children. European Journal of Dentistry. 2013; 17: 185-189.

9. Kuscu OO, Çaglar E, Sandalli N. Local analgesia-a contemporary approach: What are the techniques that provide painfree local analgesia for children? In: Splieth $\mathrm{CH}$. Revolutions in pediatric dentistry. Quintessence Publishing, Berlin. 2011: 135-150.

10. Hysi D, Caglar E, Droboniku E, Toti C, Petro E, et al. Role of video-assisted lecture on changing Albanian undergraduate students' opinion regarding pain-free dental injections in children. Acta Stomatologica Croatica. 2018; 52.

11. Hysi D, Caglar E, Droboniku E, Toti C, Kuscu OO. Dental caries experience among Albanian pre-school children: a national survey. Community Dental Health. 2017; 34: 46-49.

12. Hysi D, Kuscu OO, Droboniku E, Toti C, Xhemnica L, et al. The prevalence and etiology of Molar-Incisor Hypomineralization (MIH) among the 8-10 years old children in Tirana, Albania. European Journal of Paediatric Dentistry. 2016; 17: 75-79.

13. Ujaoney S, Mamtani M, Thakre T, Tote J, Hazarey V, et al. Efficacy trial of Camouflage Syringe to reduce dental fear and anxiety. European Journal of Paediatric Dentistry. 2013; 14: 273-278.

14. Kuscu OO, Sandalli N, Caglar E, Meechan JG. Use of preinjection diffusion of local anesthetic as a means of reducing needle penetration discomfort. Acta stomatologica Croatica. 2014; 48: 193-198.

15. Kudo M. Initial injection pressure for dental local anesthesia: effects on pain and anxiety. Anesthesia Progress. 2005; 52: 95-101. 